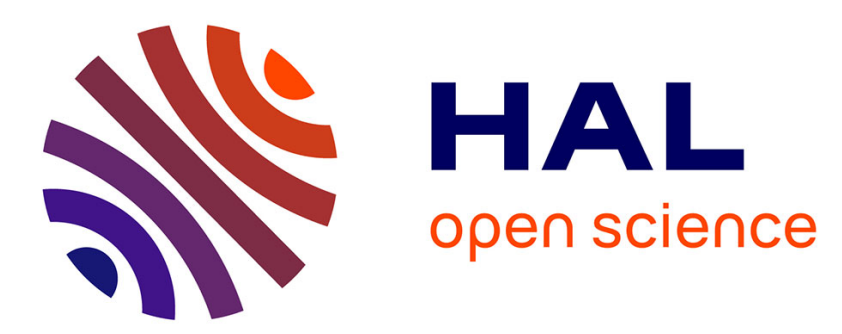

\title{
From a Subtractive to Multiplicative Approach: A concept-driven interactive pathway on the selective absorption of light
}

\author{
Laurence Viennot, C. de Hosson
}

\section{- To cite this version:}

Laurence Viennot, C. de Hosson. From a Subtractive to Multiplicative Approach: A concept-driven interactive pathway on the selective absorption of light. International Journal of Science Education, 2014, 37 (1), pp.1 - 30. 10.1080/09500693.2014.950186 . hal-01663280

\author{
HAL Id: hal-01663280 \\ https://hal.science/hal-01663280
}

Submitted on 18 Dec 2017

HAL is a multi-disciplinary open access archive for the deposit and dissemination of scientific research documents, whether they are published or not. The documents may come from teaching and research institutions in France or abroad, or from public or private research centers.
L'archive ouverte pluridisciplinaire HAL, est destinée au dépôt et à la diffusion de documents scientifiques de niveau recherche, publiés ou non, émanant des établissements d'enseignement et de recherche français ou étrangers, des laboratoires publics ou privés. 
This article was downloaded by: [University Paris Diderot Paris 7], [cecile de Hosson] On: 15 September 2014, At: 05: 17

Publisher: Routledge

Informa Ltd Registered in England and Wales Registered Number: 1072954 Registered

office: Mortimer House, 37-41 Mortimer Street, London W1T 3J H, UK

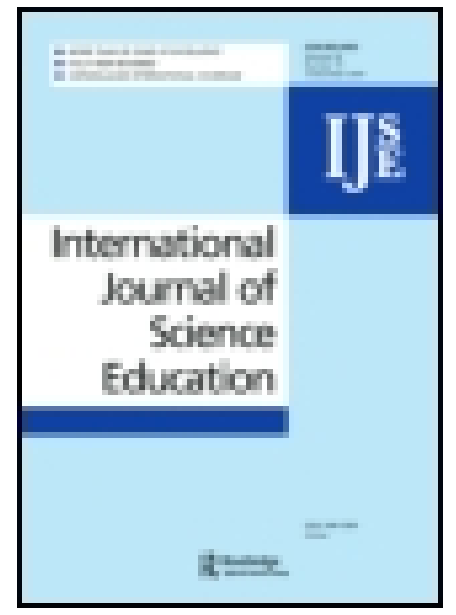

\title{
International J ournal of Science Education
}

Publication details, including instructions for authors and subscription information:

http:// www.tandfonline.com/loi/ tsed20

\section{From a Subtractive to Multiplicative Approach: A concept-driven interactive pathway on the selective absorption of light}

\author{
Laurence Viennot $^{a} \&$ Cécile de Hosson ${ }^{a}$ \\ a PRES Sorbonne Paris Cité, Université Paris Diderot, Fr, LDAR, \\ Paris, Cedex 13, France \\ Published online: 27 Aug 2014.
}

To cite this article: Laurence Viennot $\&$ Cécile de Hosson (2014): From a Subtractive to Multiplicative Approach: A concept-driven interactive pathway on the selective absorption of light, International J ournal of Science Education, DOI: 10.1080/ 09500693.2014.950186

To link to this article: http:// dx. doi.org/ 10.1080/09500693.2014.950186

\section{PLEASE SCROLL DOWN FOR ARTICLE}

Taylor \& Francis makes every effort to ensure the accuracy of all the information (the "Content") contained in the publications on our platform. However, Taylor \& Francis, our agents, and our licensors make no representations or warranties whatsoever as to the accuracy, completeness, or suitability for any purpose of the Content. Any opinions and views expressed in this publication are the opinions and views of the authors, and are not the views of or endorsed by Taylor \& Francis. The accuracy of the Content should not be relied upon and should be independently verified with primary sources of information. Taylor and Francis shall not be liable for any losses, actions, claims, proceedings, demands, costs, expenses, damages, and other liabilities whatsoever or howsoever caused arising directly or indirectly in connection with, in relation to or arising out of the use of the Content.

This article may be used for research, teaching, and private study purposes. Any substantial or systematic reproduction, redistribution, reselling, loan, sub-licensing, systematic supply, or distribution in any form to anyone is expressly forbidden. Terms \& 

and-conditions 


\title{
From a Subtractive to Multiplicative Approach: A concept-driven interactive pathway on the selective absorption of light
}

\author{
Laurence Viennot* and Cécile de Hosson \\ PRES Sorbonne Paris Cité, Université Paris Diderot, Fr, LDAR, Paris, Cedex 13, \\ France
}

\begin{abstract}
This research documents the aims and the impact of a teaching experiment on how the absorption of light depends on the thickness of the absorbing medium. This teaching experiment is more specifically characterized as bringing to bear a 'concept-driven interactive pathway'. It is designed to make students analyse the absorption of light by a medium as a selective multiplication (i.e. one depending on the wavelength) of the intensity by a factor smaller than one. Six teaching interviews conducted with fourth-year university students were recorded, transcribed and coded. Their analysis led us to evaluate the importance of the main obstacle expected, that is, of restricting the interpretation of absorption/transmission phenomena to the idea of 'less light', or, equivalently, of seeing a multiplication by a factor smaller than one as just a subtraction. The students' comments at the end of the interview introduce a discussion about the links between their intellectual satisfaction, critical attitude and comprehension of the topic.
\end{abstract}

Keywords: Physics education; Conceptual development

\section{Introduction}

The area of interaction between light, matter and colour phenomena has prompted several investigations concerning students' difficulties and/or proposals for didactic interventions at various levels (for instance, Chauvet, 1996, 1999; Olivieri, Torosantucci, \& Vicentini, 1988; Planinsic \& Viennot, 2010). A common conceptual target for both types of papers-even recent ones (Martinez-Borreguero, Pérez-Rodríguez,

\footnotetext{
${ }^{*}$ Corresponding author. PRES Sorbonne Paris Cité, Université Paris Diderot, Fr, LDAR, Paris, Cedex 13, France. Email: laurence.viennot@univ-paris-diderot.fr
} 
Suero-López, \& Pardo-Fernández, 2013)—has been the set of rules for additive and subtractive synthesis in their usual form, typically: With red light plus green light, you see yellow, or a red pigment absorbs a green light. We have discussed the limitations of such 'all or nothing' statements of these rules - statements which leave no room for the intensity of light (Viennot \& de Hosson, 2012a, 2012b). Concerning additive mixing, there must be a balance between the intensities of the lights involved in the synthesis for its outcome to conform to the usual rule. Concerning filters and pigments, what makes intensity a relevant factor is that the absorbing and reflecting powers of a pigment, for instance, are expressed by coefficients comprised between 0 and 1 , never equal to either number. Even with a small coefficient of reflection, the impact of a beam of light on a pigment will thus be visible, provided the incident light is intense enough. The multiplicative aspect of these phenomena thus emerges as a crucial condition for their understanding, whereas the common label 'subtractive mixing' does not suggest a multiplicative process. In the papers just cited, we documented some obstacles and possible facilitating conditions concerning this change from a subtractive to multiplicative analysis. The importance of such a change goes beyond colour mixing, as suggested for instance by a previous investigation on light and vision (de Hosson \& Kaminski, 2007). The scope of this paper is to extend the range of this discussion to the absorption of light by thick transparent media. Then, the multiplicative process results in an exponential dependence on thickness. The situation involved in this case, as in the preceding investigation, may be seen as a direct illustration of an exponential dependence. In this sense, it can provide access to a deep comprehension of this function. Obstacles and possible facilitators to a comprehension of this aspect constitute the main target of the investigation described here. To our knowledge, there are very few investigations available on this theme in physics education research. In contrast, a common difficulty in passing from additive to multiplicative thinking has long since been identified in mathematics, for instance, with the problem of scaling up a puzzle knowing what is added to one dimension of a given piece (Brousseau, Brousseau, \& Warfield, 2008).

\section{A Concept-Driven Interactive Pathway: Rationale and research questions}

We seek to know to what extent advanced students (fourth year at university) can benefit from a teaching pathway designed to stress how the absorption of light depends on the thickness of the absorbing medium. The focus is on the multiplicative aspect of this phenomenon, and ultimately on the meaning of the exponential function.

Our investigation is set in the framework of didactical engineering (Artigue, 1994) where some hypotheses on the expected teaching learning processes can be tested through the confrontation of an a priori and an a posteriori analysis. In this perspective, the design of a teaching sequence is explicitly organized on the basis of certain expectations ('hypotheses') concerning a given set of variables, of why these are relevant and of how they are supposed to facilitate certain targeted intellectual processes. The $a$ posteriori analysis compares what is observed and what was expected as regards the 
impact of these variables. But the term 'a priori' should not be misunderstood. ' $A$ priori' expectations do not stem from nothing. They are usually the result of a confrontation between previously known common ideas or typical students' reactions and the targeted comprehension. They usually involve what one assumes is logical intellectual functioning on the students' part, albeit on sometimes erroneous premises. In our case, little in research literature concerned the topic addressed. Therefore, we had to work out our primary expectations. In order to refine the a priori analysis, we chose to conduct a preliminary investigation. Drawing on the teaching experiment method (Komorek \& Duit, 2004), we designed the conditions for a 'concept-driven interactive pathway' (CDIP). This takes the form of a series of events-input from interviewer, reactions from the student, possibly experiments, questions and requests, discussions-orientated towards conceptual acquisition. The interaction between interviewer and interviewee is strongly structured and guided, and allows students to expose their initial thoughts and their reactions to various events. As suggested by Komorek and Duit's label, the main goal is acquisition of knowledge by the researchers (an experiment), but which makes use of a format close to that of a teaching situation. We use the label 'concept-driven interactive pathway' to underline several aspects of this type of interaction, seen here as a research tool although close to a 'teaching-learning' format.

First, the CDIP is centred on conceptual acquisition. Of course this may be seen as indirectly favouring other types of acquisition, but the strong guidance sometimes in play might be strongly criticized if, for instance, inquiry skills were the first target.

Second, it stages an intellectual interaction-here restricted to two people, but which can be enlarged to a group-following a Vygostkyan line (2012) and taking into account the 'zone of proximal development (ZPD)' of the learner. In such a perspective, it is essential to pinpoint the knowledge that is available to the targeted audience with a particular attention to the fact that what is 'already there' might be reorganized and extended during the interaction.

Third, the CDIP is progressive, which means that what is understood at one given step may serve to construct the next stage of knowledge.

Here, we do not consider that such a CDIP directly provides the pattern for a possible sequence. Rather, we propose this intellectual pathway to students in order to obtain preliminary access to some aspects of their common reactions. We want to put to the test our expectation concerning students' difficulties, which was, briefly put, a purely subtractive analysis of the absorption of light.

Thus, it might be said that inherent to the teaching experiment method is a double expectation. A first goal is to document students' ideas and ways of reasoning in a particular domain of content matter. A second goal is to observe their reactions to various types of input from the interviewer. But it is quite debatable whether the very existence of 'students' ideas' can be imagined independently from the question posed (Viennot, 1979), the problem to be solved or the argument that is presented by someone else. It has long been argued that what is sometimes called 'the context' (Champagne, Gunstone, \& Klopfer, 1985a, 1985b; see also Hewson \& Hewson, 1988) may strongly affect the type of response students give, or at least the way we 
categorize these responses. Thus, some early techniques explicitly made room for a variety of 'instances' or 'events' (Osborne \& Gilbert, 1980). We think that, for a meaningful investigation of students' ideas and ways of reasoning, the various events should encompass more than a mere set of different physical situations, they should comprise various interactive scenarios. The whole question then becomes how to construct, despite this standpoint, a synthetic description of these contextualized ways of thinking, which means looking for those aspects of the context, in a broad sense, which are decisive for students. In such a perspective, describing the type of teaching interview in play does not make any claim about its efficacy or inefficacy as a teaching tool. Nor is it simply the description of a tool intended to dig out students' ideas that would exist in themselves. Rather, we see such a description as providing constitutive information about the very meaning of students' responses.

As said above, the outcome of our limited investigation might inform further research on the design and evaluation of a teaching-learning sequence on this particular topic. As for the value of the more general features of a CDIP for teaching, it is clear that it can only be discussed here in the light of some results, but in no way evaluated as such.

We have in mind a complementary perspective: seeing how an exigent but progressive approach may, or may not, foster students' 'intellectual satisfaction' (Viennot, 2006), despite non-negligible obstacles. This might be defined as 'a feeling linked to the impression of having understood a complex topic to a certain extent, one that can be identified quite clearly, this being accomplished with a good quality/cost ratio' (Mathé \& Viennot, 2009). Such a feeling is envisaged here as a possible product of the interaction between student and interviewer. This second perspective is not, in this study, supported with a strong experimental set-up, given that we will collect only a few clues in this respect. But we think it important to situate our investigation along this line of concern, which is consistent with a relatively high level of intellectual ambition, and with the very notion of a CDIP. Here we will use the label 'metacognitive/affective' for that multifaceted component of students' reactions.

\section{Content Analysis and Targeted Conceptual Steps}

In terms of prerequisites, given their academic level, the interviewees were expected to have already been presented with the following conceptual elements:

- What the curve of transmission of a solution is, which implies the notion of selective transmission.

- The multiplicative role of the coefficient - say $\alpha_{\lambda}$ - of the transmission of light by an object, for a radiation 'near' $\lambda$.

They were also considered as having been taught the rules of additive and "subtractive" colour mixing (see Appendix 1), but also as needing a reminder in this respect.

Transmission depends in particular on the thickness of the object. The main target of the CDIP was to analyse how the coefficient of transmission of a medium depends 
on its thickness, which requires passing from a purely subtractive view of this phenomenon to a multiplicative view. Box 1 displays how this topic can be algebraically formalized, but such formal knowledge is not targeted in this CDIP.

Box 1. Algebraic formalism to account for the role of thickness in absorbing medium

Let $\mathrm{d} I(\lambda)=i_{\lambda} \mathrm{d} \lambda$, the intensity of a radiation between $\lambda$ and $\lambda+\mathrm{d} \lambda$. We call $i_{\lambda}$ 'spectral density'.

$i_{\lambda}(0)$ and $i_{\lambda}(\mathrm{x})$ are, respectively, the values of this quantity at the entrance and at a given position ( $x$, in case of a one-dimensional problem) in the medium.

$$
i_{\lambda}(x)=\alpha_{\lambda}(x) \quad i_{\lambda}(0)
$$

Let us now examine more closely the role of the thickness.

Between $x$ and $x+\mathrm{d} x$, one has

$$
\mathrm{d} i_{\lambda}=-\beta_{\lambda} i_{\lambda}(x) \mathrm{d} x
$$

with $\beta_{\lambda}=\varepsilon_{\lambda} c$, where $\varepsilon_{\lambda}$ is a coefficient characteristic of the dissolved substance and $c$ is the concentration (Beer-Lambert's law).

Hence, given (2):

$$
i_{\lambda}(x)=i_{\lambda}(0) \mathrm{e}^{-\beta_{\lambda} \mathrm{x}}
$$

For a given object (solution in a recipient of thickness L), Equation (3) writes

$$
i_{\lambda}(\mathrm{L})=i_{\lambda}(0) \mathrm{e}^{-\beta_{\lambda} L}
$$

The quantity $\left(\beta_{\lambda} \mathrm{L} / \ln 10\right)$ is called the absorbance $\gamma_{\lambda}$. This quantity is proportional to the thickness of the medium (Beer-Lambert's law).

In other terms, $\gamma_{\lambda}$ is the decimal logarithm of the ratio $i_{\lambda}(0) / i_{\lambda}(L)$ :

$$
i_{\lambda}(L)=i_{\lambda}(0) 10^{-\gamma_{\lambda}}
$$

From Equations (1) and (4), we get

$$
\alpha_{\lambda}=\mathrm{e}^{-\beta_{\lambda} \mathrm{L}}=10^{-\gamma_{\lambda}} .
$$


For this investigation, the main conceptual target is limited to the following points.

- In order to compare the transmission curves of objects consisting of one, two, three, etc. superimposed identical layers of a given filtering material, it is necessary to understand that, for each given wavelength, each layer 'multiplies' the intensity of the incident light by a factor smaller than one, or a percentage-which is the same for each layer in this case. If the first layer transmits $90 \%$ of the light of a given wavelength, two layers transmit $90 \%$ of $90 \%$ of this light. This means that, for this wavelength, the emerging intensity is the incident one multiplied by $0.9 * 0.9$ or 0.81 , and so on. In this case, we use and authorize a facilitating expression, that of speaking of 'the light of a given wavelength', instead of 'the light in a narrow bandwidth around a given wavelength'.

- Another essential step is to realize that the multiplication factor is different for different wavelengths, in other words, that the transmission is selective. Thus, the respective rates of transmission for a 'red' or a 'blue' spectral band might be, respectively, $90 \%$ and $50 \%$. With two layers, these rates become, respectively, $0.81 \%$ and $0.25 \%$, etc. In such a case, the difference between the two rates increases dramatically with the number of layers.

Consequently, the shape of a curve giving spectral density versus wavelength may be strongly distorted when light travels in a thick medium.

\section{Research Method}

The interviewees (we will also speak of 'students') were six prospective physics and chemistry teachers in their fourth year at University Paris Diderot. In their three first years, they took and graduated in subjects including geometrical and wave optics, Newtonian mechanics, fluid statics, electromagnetism, as do all physics students. Thus, these students can be considered as very likely to have been taught what a curve of transmission of light by a transparent medium is. The interviews lasted about one hour each.

The next sections describe successively the experimental context provided to students, the scenario planned for their interaction with the experimenter, the styles of the interaction and the way the interviews were analysed.

\section{The Experiments}

This CDIP relies on some experiments-described hereafter-that are intended to have a pivotal role in the interaction.

The first experiment (E1) consisted in using the device shown in Figure 1 to display the spectrum of light having crossed the filters of increasing thickness. A 'slide' consisted of a slit equipped with transversal strips of a yellow filtering material, strips of increasing thickness: one, two, three ... six superimposed layers of same thickness. Another analogous object was provided, this time with pink-magenta filters. 


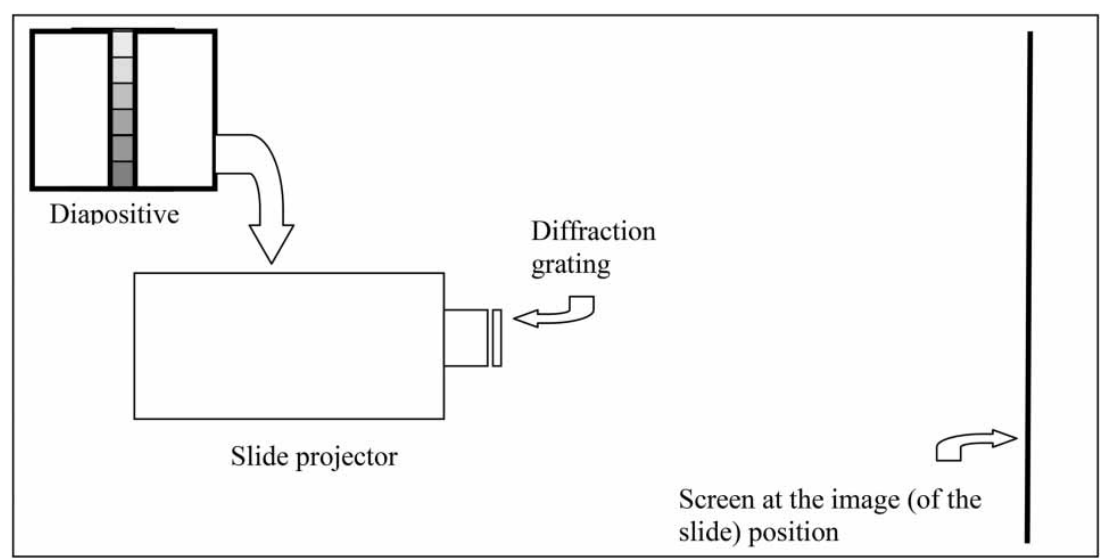

Figure 1. Sketch of a setting used to display the spectrum of filters of different thicknesses. A projector for diapositives (that might be replaced as well by any device forming a real image on the screen); a diffraction grating (here 600 lines $/ \mathrm{mm}$ ); object: A vertical slit (width about $1 \mathrm{~mm}$ ), covered with one, two, three, ..., six horizontal strips made of transparent and thin plastic: light yellow or light pink

Photos of spectra are available in Viennot and de Hosson (2013). They show, for the 'yellow slide', that the red and green parts of the spectrum are, broadly speaking, unaffected by the number of layers, whereas the luminosity in the blue part strongly diminishes with thickness, until it completely disappears with six layers. A strongly selective absorption was also observed with the pink slide.

This is a prototypical experiment, which we think a priori appropriate to help students take some distance from a purely subtractive view of absorption. In order to analyse this experiment, it is necessary to understand that, for each given wavelength, each layer 'multiplies' the intensity of the incident light by a factor smaller than one, a percentage. Hence, there is need for a multiplicative approach. Moreover, this wavelength-specific percentage is the same for each layer, because the thickness of each layer is the same. This facilitates the calculations.

It is noteworthy that, strictly speaking, the fact that the observed attenuation depends on the spectral band is not straightforward 'proof' of the selectivity of the absorption because of the possible non-linear response of the cones. When this question is broached by a student, the argument is not dispelled but the interviewee is invited to search for an interpretation that would not rely on this aspect.

Another experiment (E2) simply consisted in observing the colour of a thin (about $3 \mathrm{~mm}$ : yellow) or thick (about $1 \mathrm{~cm}$ : red) layer of pumpkin seed oil.

Finally, a discussion about the atmosphere is simply based on everyday experience.

In all of these cases, transmission curves for a 'thin' layer are provided, after a discussion aiming at clarifying the filtering role of the considered object.

\section{The CDIP: Outline of the scenario}

The CDIP designed for our investigation comprises the following main steps 
'Reminder' phase (Rem). Concerning the rules of additive mixing and the role of pigments or filters, a phase serving as reminder is proposed to students. The rules recalled in the Appendix are handed out to the interviewee, and presented as guides, in case they would need them. A colour mixer (Planinsic, 2004) is used. The students are encouraged to pose any question they feel a need for. Students are reminded that the rules stem from the existence of three kinds of receptorscones - on the retina and a complex integration of the corresponding responses in the visual system (Figure 2).

This reminder is provided to avoid any lapses in memory and to minimize any impression of being evaluated. The expression 'subtractive synthesis' is not used and the interviewer speaks of the 'absorbing role' of the filters and pigments.

At the end of this phase, students are also asked to choose which mathematical operation-adding, subtracting, multiplying and dividing-comes to their mind when considering the role of pigments or filters.

Filt-a phase (E1). Then comes a description of the device shown in Figure 1, and the students are shown the composite 'slide' that will be put in the slide projector. They can manipulate it. They can see the strips with different thicknesses, and comment on their more or less yellow colour. Then, they are presented with a sketch of a possible transmission curve for one layer (Figure 3), and asked to draw the curves accounting for the transmission of light by two, then three layers of the same material.

Filt-b phase (E1). The experiment is then performed, and the students are asked to describe what they see.

Then, the students are invited to reconsider, while interacting with the interviewer, the curves that they had previously drawn. In this strongly guided part, the goal of the

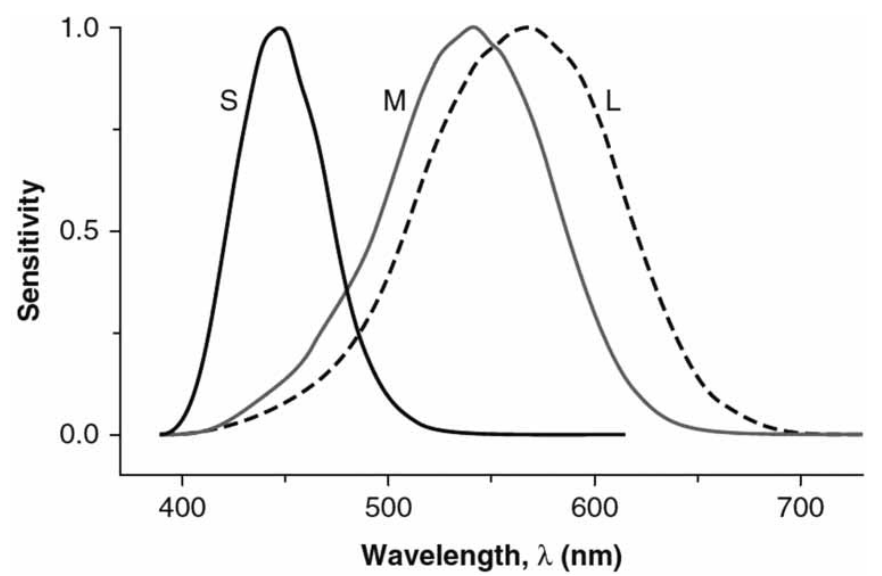

Figure 2. The sensitivity of cones for, respectively, short (S, 'blue'), medium (M, 'Green') and long (L, 'Red') from the Goldstein (2010) 


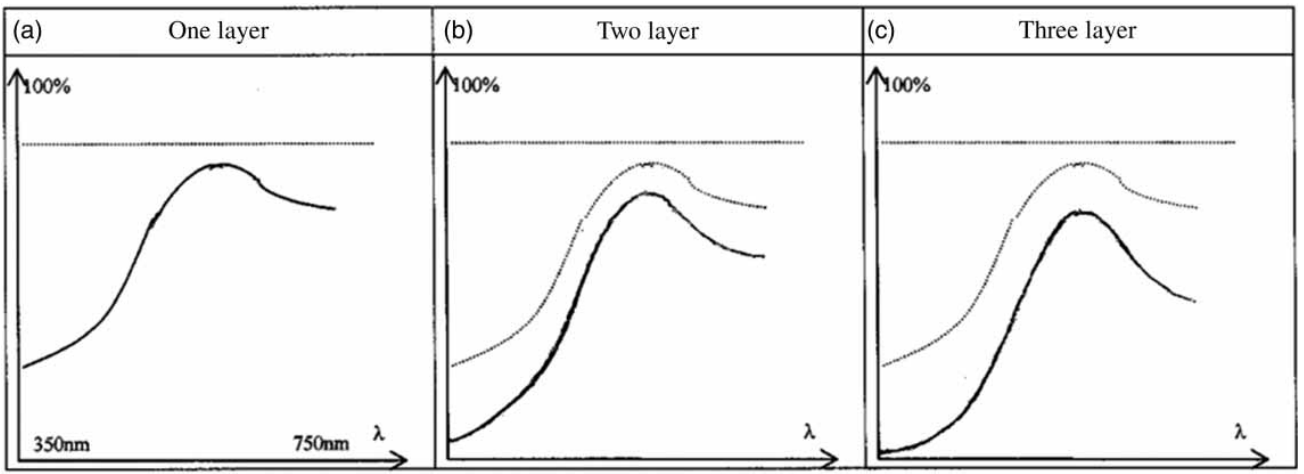

Figure 3. A sketch of the transmission curve for one (a), two (b) or three (c) layers of filtering material. The first curve was handed out to students, who were asked to draw the two others

interviewer is to assess to what extent the students become aware of the distortion of the curves (with respect to the curve for one layer), and link this fact to the multiplicative character of absorption. At the end of this phase, the students are supposed to have reached, with more or less guidance, this conceptual target.

Oil phase (E2). Then, the students are asked whether a similar process might result in the change in colour of a substance depending on its thickness. Whatever their answer, they are presented with the case of pumpkin seed oil (Kreft \& Kreft, 2007), which is yellow when applied in a thin layer and red in a thick layer. They are given a highly simplified sketch of the transmission curve of this substance (Figure 4):

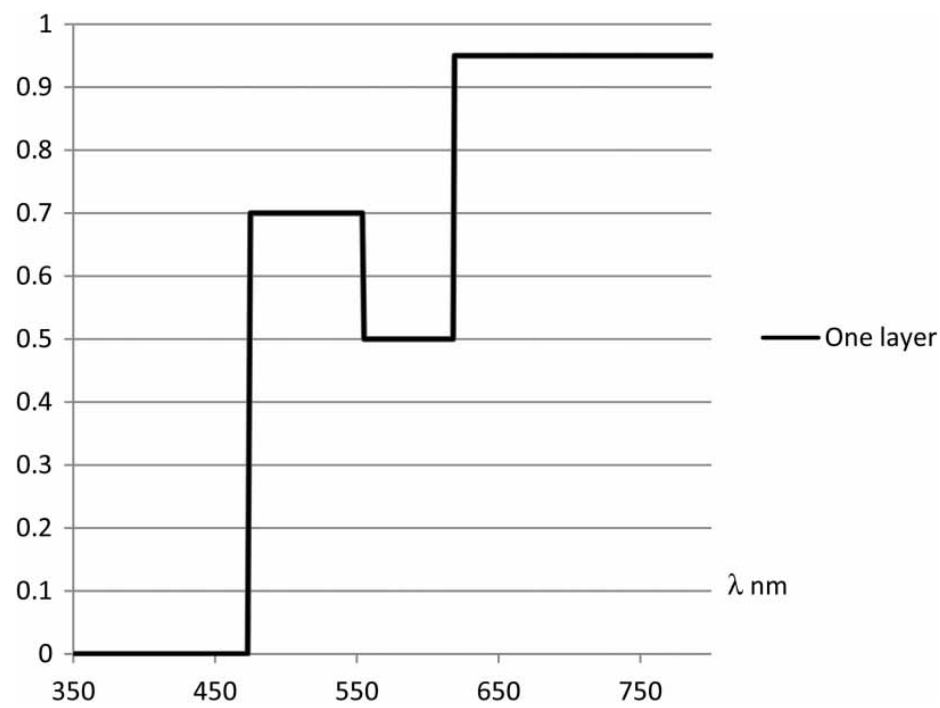

Figure 4. Transmission curve of a thin layer of pumpkin seed oil. This curve is inspired by the one shown in Kreft and Kreft's (2007) 
two crenels at $0.95 \%$ ('red') and $0.7 \%$ ('green'), with a plateau at $0.5 \%$ in between, and a zero value in the 'blue'. They are asked to explain what occurs when the thickness increases, on the basis of the transmission curves. In any case, students are shown how the transmission curves change with thickness (Figure 5). The interviewer provides a transparency with sensitivity curves at the same scale, and, if necessary, explains how these curves account for the observed colours.

Atm phase. Students are then asked to find other examples. Whatever their answer, they are asked to comment on how the colour of the Sun (or the Moon) changes throughout the day. A strongly guided discussion is intended to provide agreement on the role of the atmosphere, seen as a filter for the light coming from the Sun, given the phenomenon of Rayleigh diffusion. A curve (Figure 6) is handed out to students who are then asked to find the curve corresponding to a path in the atmosphere twice, then 3 and 10 times as long that travelled when the Sun is at Zenith. In any case, these curves (Figure 7) are shown to students after a time.

Gene phase. The previous examples make it possible to stress that the preceding analysis holds for three states of matter: solid, liquid and gaseous. Particularly with the introductive situation — solid filters with increasing numbers of layers - this analysis may constitute a first approach of what an exponential is (Box 1): the exponential is 'calculated' step by step — so to speak. Students are invited to find a link between what they have been working on and a mathematical function they might know. Whatever

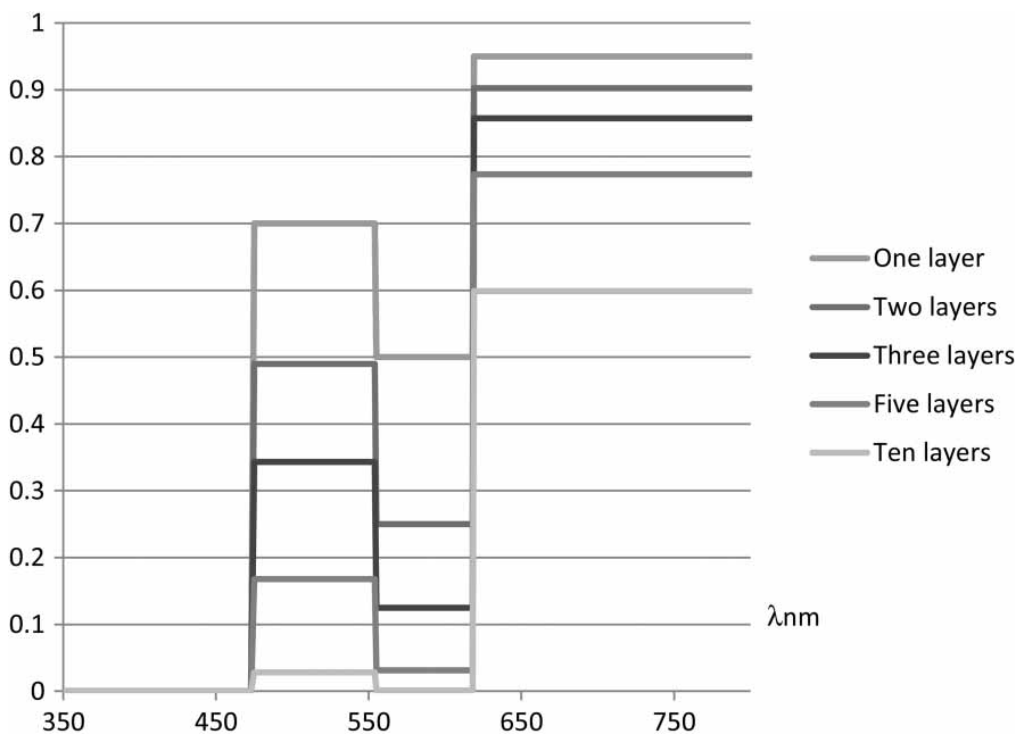

Figure 5. Transmission curve of 1, 2, 3, 4, 5 and 10 successive layers of this liquid, using the model shown in Figure 4 


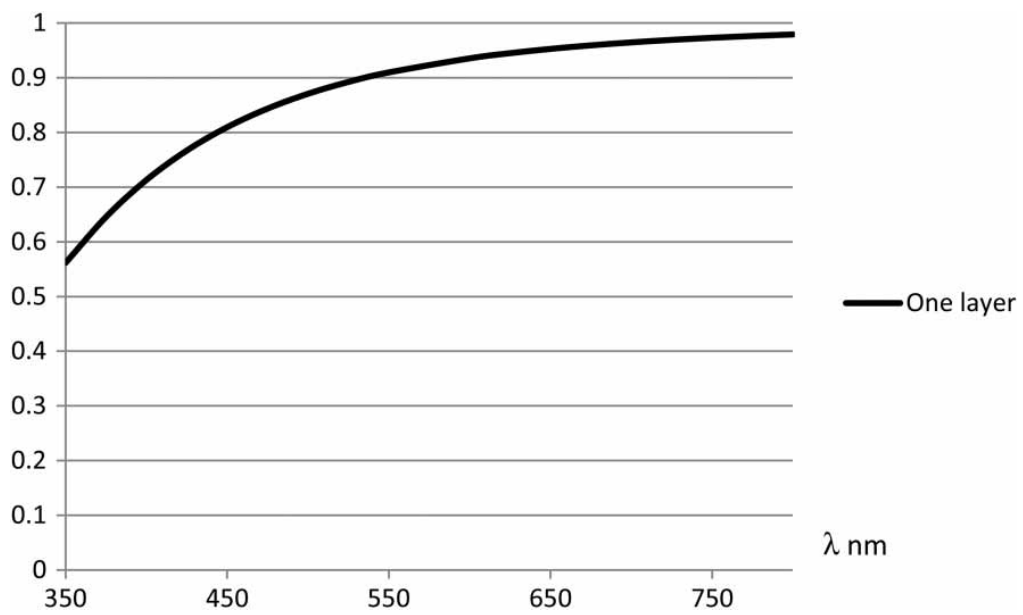

Figure 6. Transmission curve of "one layer" of the atmosphere, that is, the atmospheric path travelled by light when the Sun is at Zenith (drawing on: Vollmer \& Gedzelman 2006, p. 300.)

their answer, they are invited after a time to think about the generalization, which is made possible with the exponential.

'Metacognitivelaffective' phase (Mca). Students are asked for their global evaluation of the interview, their feeling, at the end. Students are asked to formulate their level of satisfaction, rated from 1 (poor) to 4 (very high), or to express it in a sentence should they prefer to. This is also an opportunity for them to state what they think they have learnt.

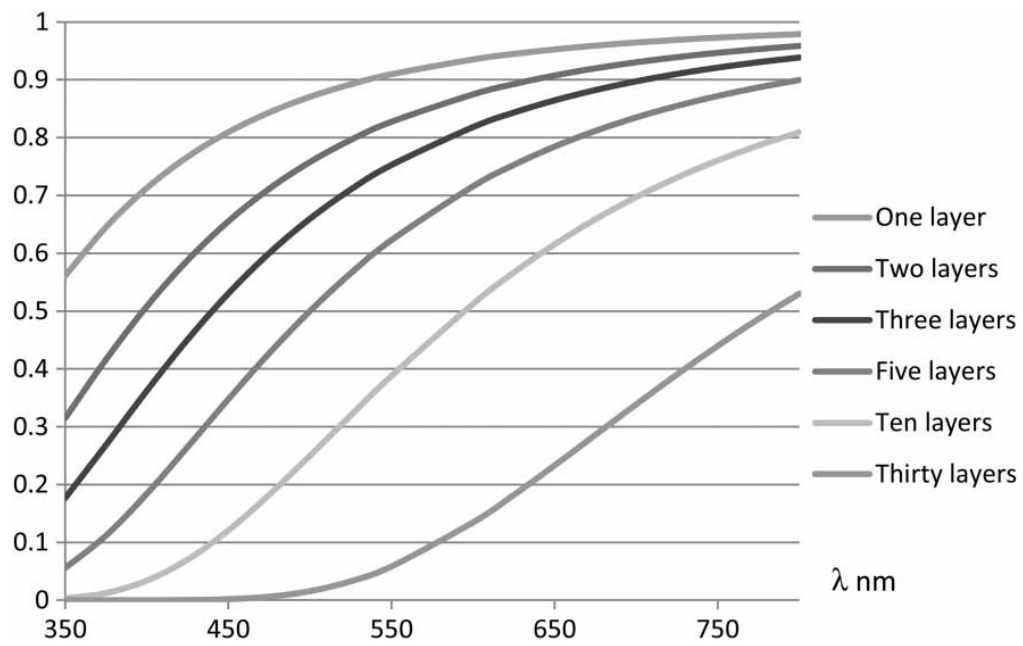

Figure 7. Transmission curve of 1, 2, 3, 4, 5, 10 and 30 successive layers of atmosphere ('One layer' is the atmospheric path travelled by light when the Sun is at Zenith), using the model shown in Figure 6 
The interviews: an overview. Table 1 outlines the main steps in the design of these interviews.

\section{Styles of Interaction}

As is consistent with our definition of a CDIP, we brought to bear a variety of styles of interaction with the students. In the first phases (Rem, Filt- $a$ and Filt-b), the structure was mainly provided by the incompatibility between the students' predictions and the spectra of the composite filter. The interviewer's input was mainly aimed at clarifying the students' lines of reasoning. Thus, after the spectra with yellow filters were shown:

Int (Interviewer): You told me that red, the top of the curve, was not that changed, so do you think we can keep this curve (translated, therefore with same shape as for one layer)?

Mi : $\quad$ It's logical, by the way, that it (the shape of the curve) changes.

Int : $\quad \mathrm{Ah}$, there is a logical reasoning, because ...?

Mi: $\quad$ Err ...it remains yellow, therefore yellow is always red plus green, therefore there is no reason why there would be less red or less green. Less and less blue as it becomes more yellow, I can understand, but it's not normal that I said there will be less red and less green ... (as with the downwards translated curve)

Int : $\quad$ Yes, not 'normal', but it might be a common answer. When you see the curve (for one layer) you might be tempted to say this, but now you tell me, if the filter is doing its job correctly...

Mi: $\quad$ There is no particular reason for red and green to be blocked off.

Int : $\quad$ There is no reason to block them off (red and green). Then, we should drop this story. Well, you told me that the mathematical operation that came to your mind ... you told me I have a translation. That's what you told me. The mathematical operation that came to your mind would be ...

Mi: $\quad$ Subtraction.

The interviewer's role may change notably when a difficulty blocks off the planned intellectual progress:

Int : When you tell me we take off the blue, you are in ...

Mi : $\quad$ Subtraction

Int : $\quad$ That's what strikes you.

Mi: $\quad$ It's more of a proportional diminution.

Int : $\quad$ Proportional diminution: Isn't there a simple operation (that might be) called 'proportional diminution', which sums up 'proportional diminution' ...

Mi: When I was speaking of multiplication, it's true that with a number smaller than 1 , it's a division.

Int: It's a multiplication by a number smaller than 1 (...) Basically, it's multiplicative (...). We passed from - at least did I try to suggest this - from a view - you're the one who said this - a subtractive view, from a diminution, we might say, but - the important word - a proportional diminution, to something slightly difficult for you to formulate: it's multiplied by a number smaller than 1 . 
Table 1. Main steps in the teaching interview

\begin{tabular}{|c|c|c|c|}
\hline Phase & $\begin{array}{l}\text { Our conceptual targets } \\
\text { and questions }\end{array}$ & Material setting & $\begin{array}{l}\text { Main aspects of the } \\
\text { interaction (planned } \\
\text { and/or expected) }\end{array}$ \\
\hline Rem & $\begin{array}{l}\text { Students are reminded of } \\
\text { the classical rules } \\
\text { First observation of their } \\
\text { reactions } \\
\text { Question: which operation } \\
\text { comes to your mind: }+,-,,^{*}, \\
\text { ? }\end{array}$ & A colour mixer & $\begin{array}{l}\text { The students appropriate } \\
\text { the classical rules; } \\
\text { predictions on this basis, } \\
\text { observation, discussion, } \\
\text { recapitulation. } \\
\text { Table of rules left to } \\
\text { students } \\
\text { Question 'which operation } \\
\text {...?' }\end{array}$ \\
\hline Filt-a & $\begin{array}{l}\text { Draw the curves accounting } \\
\text { for the transmission of light } \\
\text { through two, then three } \\
\text { layers of the same material: } \\
\text { Do students just translate } \\
\text { the first curve downwards, } \\
\text { or do they/how do they } \\
\text { change the shape of the } \\
\text { curve? }\end{array}$ & $\begin{array}{l}\underset{\mathrm{C}}{\mathrm{P}} \\
\text { of Device to project spectra } \\
\text { through each strip }\end{array}$ & Predictions with arguments \\
\hline Filt- $b$ & $\begin{array}{l}\text { Performing the experiment: } \\
\text { Do they change their } \\
\text { curves? Formulate a } \\
\text { conclusion explicitly using } \\
\text { selective multiplication? }\end{array}$ & Spectra observed & $\begin{array}{l}\text { Students asked to } \\
\text { reconsider the curves, to } \\
\text { account for the } \\
\text { disappearance of 'the blue': } \\
\text { strongly guided discussion }\end{array}$ \\
\hline Oil & $\begin{array}{l}\text { Observe colours of the oil, } \\
\text { then apply a multiplicative } \\
\text { procedure to the curve } \\
\text { proposed by the interviewer } \\
\text { to account for these colours }\end{array}$ & $\begin{array}{l}\underbrace{1}_{0} \sqrt{\square} \\
\text { consitivity curves of the } \\
\text { cones on transparency }\end{array}$ & $\begin{array}{l}\text { The interviewer } \\
\text {-provides help for } \\
\text { calculation } \\
\text {-explains how to use the } \\
\text { sensitivity curves of the } \\
\text { cones }\end{array}$ \\
\hline Atm & $\begin{array}{l}\text { See the situation as a } \\
\text { filtering case. Transform the } \\
\text { curve provided by the } \\
\text { interviewer for 'one layer' }\end{array}$ & $\begin{array}{c}1 \\
0.5 \\
0 \\
\end{array}$ & $\begin{array}{l}\text { The interviewer provides } \\
\text { help for } \\
\text {-interpretation of the } \\
\text { situation as a case of filtering } \\
\text {-calculation }\end{array}$ \\
\hline Gene & $\begin{array}{l}\text { Ask about a function } \\
\text { accounting for the changes } \\
\text { of intensity observed }\end{array}$ & & $\begin{array}{l}\text { Input from the interviewer: } \\
\text { (selective) exponential } \\
\text { decrease }\end{array}$ \\
\hline$M c a$ & $\begin{array}{l}\text { Global evaluation of the } \\
\text { design }\end{array}$ & & Interviewees express feelings \\
\hline
\end{tabular}


At times, the interviewer's style becomes clearly declarative and directive, despite the dialogic structure of some parts of the discussion. This is the case, for instance, when the interviewee is reminded of the law of Rayleigh diffusion, or how to use the sensitivity curves of the cones.

\section{Processing and Analysing the Interviews}

The interview transcripts were submitted to a thematic content analysis, each category being defined by a theme that could be identified in the students' comments (Table 2). We used two types of categories. Some originate in our a priori analysis and others emerge from the transcripts (Strauss \& Corbin, 1990). This process was conducted independently by the two authors and the final classification emerged from a negotiation between them.

The different parts of the interview do not give rise to the same type of analysis. The first part, which comprises the first three phases, ends when the multiplicative aspect of absorption is recognized. It is analysed in detail. All that concerns the situations proposed for transferring the multiplicative analysis is more globally reported here, the question being: Are there any particular difficulties or obstacles concerning this transfer?

The question concerning a possible generalization is posed mainly as an introduction to the interviewer's intervention. The goal is to wrap up the whole interactive pathway via the introduction of the exponential function. In case the interviewee has difficulty expressing this idea himself, the answer to this question is soon provided by the interviewer, due to time constraint.

Concerning the students' feelings, beyond their rating on a Likert scale (from 1, low intellectual satisfaction to 4 , high intellectual satisfaction), their comments will be cited.

Table 2 displays the main thematic categories used in the analysis of the interviews. For the sake of compactness, the short descriptions displayed in the first column will be illustrated only in the section on results.

\section{Results}

The impact of the didactic intervention was measured through the analysis of the recordings and scripts of the six interviews. All student interventions are cited using student pseudos and with the time elapsed since the beginning of the part of the interview that is considered.

The first three phases (i.e. the first part) of the interview were intended to lead the student teacher to acknowledge the value of a multiplicative analysis in interpreting the role of the thickness of the absorbing medium. The following phases (i.e. the second part) bring to bear a transfer of this conceptual element to two other situations, then a linkage to the exponential function. The last phases will be accounted for in a second step. 
Table 2. Main thematic categories used in the analysis of the interview

Theme

Code in Tables 3 and $4^{*}$

Absorption: the word is taken up by the

interviewee

Subtractive synthesis first mentioned by the

S

interviewee

Subtractive synthesis first criticized by the

CritS

interviewee

Less light, lower intensity

Selection, selective change

Shrinking of spectral bandwidth

Proportional change

Percentage first mentioned by the interviewee

$\mathrm{X} \%$ of $\mathrm{Y} \%$

Mathematical operation suggested by the

interviewee

$/ 2 / 3$

Transmission curve translated (same shape)

Not translated (not same shape)

Ambiguous

Colour change with thickness possible/

impossible

Oil seen as multi-layer filter

oiF

Change of colour: the Sun spontaneously

cited,

Selective diffusion by the atmosphere

Atmosphere seen as multi-layer filter

Exponential funct. or $\mathrm{e}^{-\mathrm{kx}}, \mathrm{A}^{\mathrm{n}}$ first mentioned

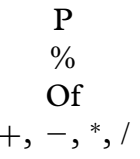

Transmission by 2,3 layers $=_{1 / 2,1 / 3}$ of what is transmitted by 1 layer

by interviewee

Intellectual satisfaction (rating)

Intellectual satisfaction linked to self-esteem

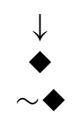

${ }^{*}$ To facilitate readability, the other codes are omitted in Tables 3 and 4 . The results bearing on these (here) non-coded categories are summed up in the text. When a code is mentioned in light grey in Tables 3 and 4, it means that the corresponding idea has been accepted after strong guiding. When a theme, such as multiplication, is not explicitly mentioned although it seems that it is guiding the interviewee's decisions, as when he is doing a multiplication, then the corresponding symbol is put between parentheses.

\section{The First Three Phases: Towards a Multiplicative Analysis}

Table 3 displays the main themes mentioned by the interviewees during the first part (first three phases) of the interview.

\section{Rem Phase}

This part of the interview was devoted to reminding the students of the classical rules about colour mixing, in a context of change depending on the presence/absence of the 
Table 3. Themes expressed by the interviewees during the three first phases of the discussion



The themes are shown with the symbols displayed in Table 2, exponents mean the number of times the theme is mentioned by the interviewee. The symbols $\lambda_{\mathrm{s}}$ and $\nabla_{\mathrm{s}}$ designate, respectively, the time when the first curve (for one layer of yellow filter) was handed out to the interviewee and the time when the corresponding experiment was performed.

beams. Placed in this context, the students seemed to be rapidly at ease. No particular difficulty was encountered, even with students who had little recollection of school learning in this field. This does not mean that the students had reached a sound comprehension of colour phenomena, especially as concerns absorption, even if nearly all (5/6) the students alluded to this concept as early as the Rem phase. All of the interviewees linked the rules concerning the pigments or filters to the mathematical operation of subtraction, with, in one case $(C h)$, the variant of a 'negative addition'. Several times, an explicit link was made between this answer and the idea that, with a filter, something is 'taken off'.

Mi 5'15: Er rather... absorbed, there is really something taken off.

Int. Taken off. That's what makes you want to say 'subtraction'

Mi: $\quad$ That's it.

Ch 4'30: One wavelength is taken off, the other one can pass.

In this respect, two students ( $M i$ and $Y a)$ spontaneously recalled the current label 'subtractive synthesis'. 
Table 4. Themes expressed by the interviewees throughout the discussion, during the phases bringing to bear a transfer to two different situations (Fil-oil, Fil-atm and Gene)

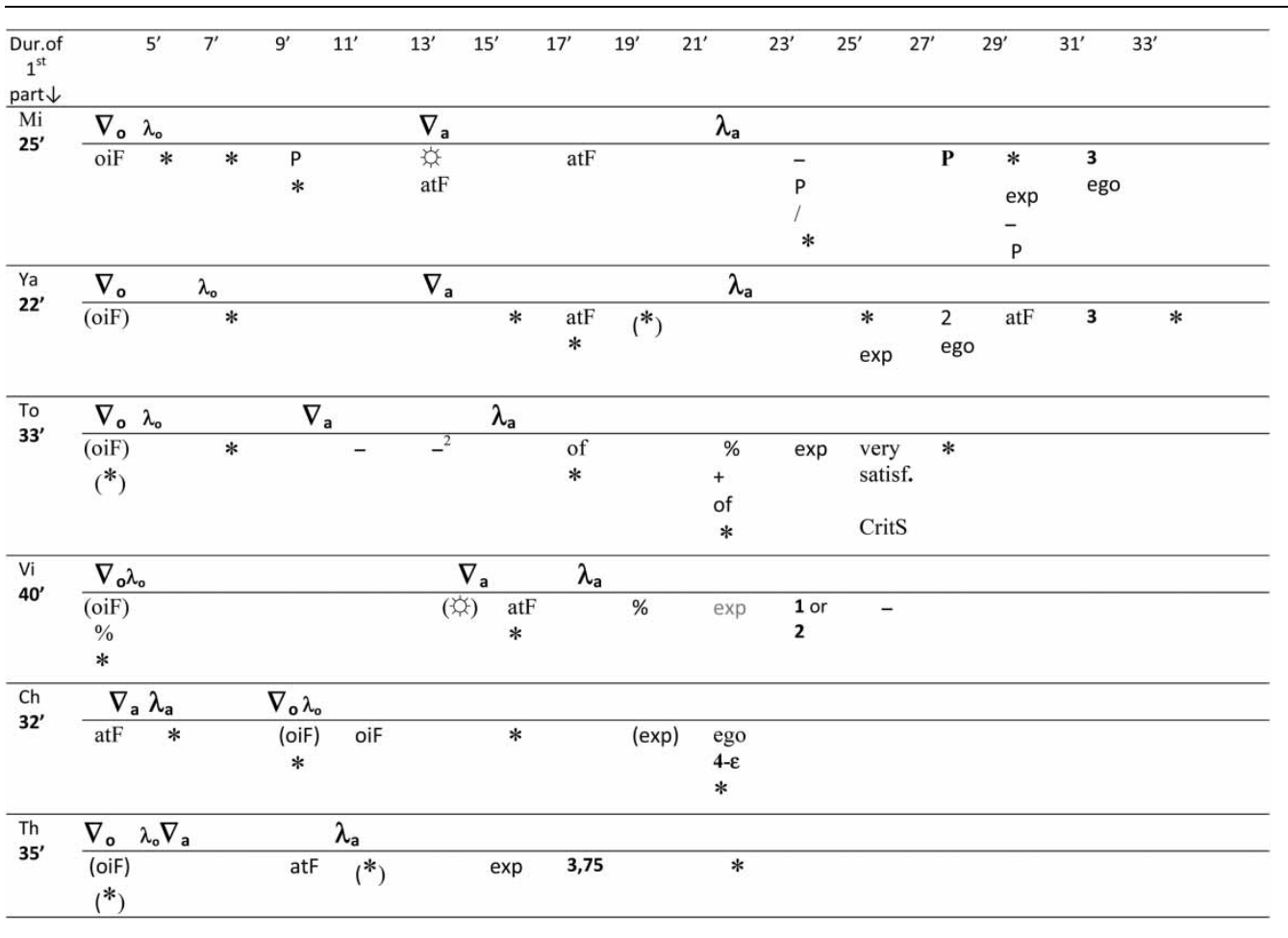

The themes are shown with the symbols displayed in Table 1, exponents mean the number of times the theme is mentioned by the interviewee. The chronology is suggested, starting for the beginning of this second part. The symbols $\nabla_{\mathrm{o}}$ and $\nabla_{\mathrm{a}}$ designate, respectively, the times when a new situation (oil, atmosphere) is introduced with, soon after, the corresponding curve (for one layer: $\lambda_{\mathrm{o}}$ and $\lambda_{\mathrm{a}}$ ).

\section{Filt phases}

The phase involving solid filters is twofold. We sum up the main results hereafter.

\section{Filt-a: Predicting the absorption curves of the multi-layer filters}

The Filt- $a$ phase is dedicated to predictions about the transmission curves of two-layer or three-layer filters. It took between 4'30 and 6'40 depending on the interviewee.

Most of the interviewees drew curves that seemed translated downwards from each other (Figure 8), and spoke abundantly of the fact that with several layers less light was transmitted.

Thus, Figure 8 shows nearly parallel curves drawn by $M i, T o, Y a$ and $C h . M i$ and $T o$ made unambiguous comments:

Mi 9'24: They have the same shape, but not the same maximum value.

Int 20'07 : Err, so err .... it's not only for the maximal value.

Mi : $\quad$ A shift. 


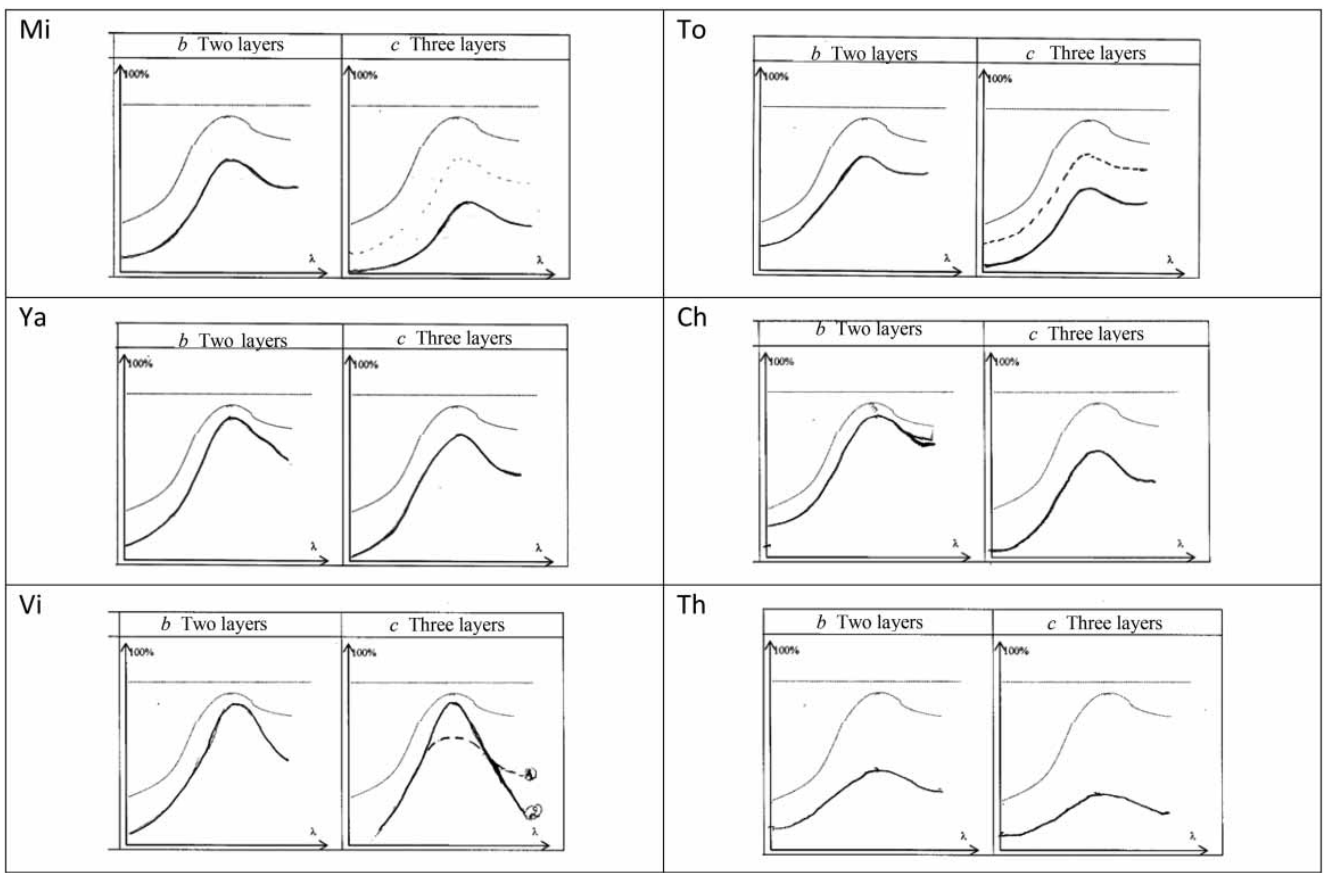

Figure 8. Transmission curves for two and three superimposed filtering layers drawn by students before the corresponding experiment.

The justifications referred to wavelengths that were 'transmitted or not'

To 10'41 : Given that there are several layers ... that light travels across the different layers, there's no reason why it would change the different wavelengths which are transmitted or not, you know.

However, it was not always clear whether statements like 'same shape' or 'downward translation' were used with their proper meaning by the interviewees. Some curves that may seem to have been translated from each other are accompanied by dubitative comments. Thus, Ya 7'30 explicitly used, for one point, a multiplicative procedure with percentages, but kept speaking of a translated curve, which fits his drawing for three layers. Then, he expressed some doubts, and finally clearly formulated his thought:

Ya 8'02: It's nearly the same, but normally it should be more and more deformed.

Ya 8'57: It's the same shape, but it gets flatter and flatter.

Int : Is it a translation?

Ya : $\quad$ No

$C h$ was ambiguous in his statements, after having drawn curves that seemed translated from each other:

Ch 8'37: The curve will look more or less the same, because it's always the same wavelengths that are absorbed no matter what $(\ldots)$ The contrast will be slightly stronger ( ...) We'll make the curve slightly sharper.

Ch 10'37 :By and large, it's a subtraction. 
By contrast, $V i$, after having drawn parallel curves, was very soon able to predict that the curves for several layers would have different shapes. Finally, Th (8'30, 14'20) relying on (imprecise) memories about Beer-Lamberts' law, said and confirmed with his drawings that the transmission curve for $n$ layers could be obtained by dividing the values corresponding to one layer by $n$.

During this phase, only two students ( $Y a$ and $V i$ ) used an expression of the type $\mathrm{X} \%$ of $\mathrm{Y} \%$ for deducing the curve corresponding to several filtering layers from that relative to one layer. Moreover, the idea that the multiplication was a relevant operation for the case under study was only expressed by $\mathrm{Ya}$, who was also able to analyse his own way of reasoning retrospectively:

Ya 9' 30: Actually, I was not seeing the curve as a whole, I was considering a fragment of the curve that, locally, I thought, had the same value and this fragment got smaller and smaller each time.

The general impression left by these first answers (Filt-a) is that, at best, some aspects of comprehension have been reached without a real conceptual command of the role of multiplication in this case.

It is also noteworthy that the word 'absorption' was never used by these students during this phase of prediction.

\section{Filt-b: Accounting for the observed spectra with absorption curves}

The interviewees were shown the spectra of white light passing through the composite object made of one, two, $n$ layers of yellow filter (Figure 1). Once these spectra were observed, it was very soon clear to everyone that, for several superimposed layers, 'the blue' was more absorbed than 'the red' and 'the green'. The change in the shape of the curve was more or less rapidly acknowledged by those who had not predicted it.

The idea that the spectra were 'shrunk', 'reduced', 'truncated' or that there was a selective diminution of the curve was expressed by all:

Ch 14'06: The curve gets thinner.

The students' reactions were diverse.

$M i$ realized that he might have predicted this effect with a simple argument, already cited:

Mi 14 '08 : Besides, it's logical, that it does not change ( $\ldots$ ). It stays yellow. Yellow always results from adding red and green $(\ldots)$ Actually, there's no reason why there should be less red and green. It's strange that I said there would be less red and green.

Ch searched to conciliate this fact with the idea of translation:

Ch 14'34 : If it (the curve) is translated downwards, the blue we've just seen disappears ... so, the blue is lost, so it's OK.

$V i$ expressed his surprise: 
Vi 23': Wavelengths like red are much less diminished than I thought.

A minority (To 19'20, Th 8'47) suggested dividing the transmission rate of one layer by two when two layers were superimposed, in one case $(T h)$ by calling explicitly on uncertain memories concerning the Beer-Lambert law (Box 1).

In terms of mathematical operations, subtraction remained the most pregnant by far, even after the change in the shape of the transmission curve was acknowledged:

Int 25'12: What did you use when constructing your answer, a line of reasoning founded on which type of operation?

Vi: $\quad$ Subtraction, mainly

To 18 '30 : We add subtractions.

The theme of selection was linked to subtraction:

Vi 26'32: Subtraction doesn't occur for all the colours.

Ch 14'36 : It's still a subtraction, a wavelength is taken off.

Int $18^{\prime} 45$ : Even getting the peak thinner is a subtraction?

To : $\quad$ Yes it's ..., yes, still subtraction. Blue is taken off.

It was observed that even a product of percentages was formulated as a subtraction:

Mi 21'50 : Ninety per cent of ninety, it's ninety minus ...

Int : Minus ?

Mi : $\quad$ Ninety minus nine divided by a hundred.

The multiplicative status of absorption was slow to emerge: from 10' to 15' (Table 3) save for $\mathrm{Ya}$ who had already expressed this idea in the preceding phase. With To and $V i$, the interviewer herself finally (after respectively, 11' and 13' in this phase) had to introduce in the discussion the usefulness of multiplication for this analysis. Even after having acknowledged the relevance of multiplication in this problem, some students expressed their lack of conviction:

Vi 27 ’50 : It may come down to a division. If you put this as a proportion, it may even come down to a subtraction.

Ya 18'47 : It's compatible, but actually it might well be additive.

The first of these comments might refer to a formal equivalence; the second is backed up by an allusion to the non-linearity of the visual system's response. Both witness, we suggest, that their reluctance to passing to a multiplicative analysis is not counterbalanced by a direct and clear comprehension of what absorption is.

The idea of multiplication seems to have been arrived at, in most cases, through that of proportionality, and the expression ' $\mathrm{X} \%$ of $\mathrm{Y} \%$ '. However, it also appears that, for some students, this expression is not clearly equivalent to a multiplication, even after they have done a correct calculation. Thus, important shifts can be observed in Table 3 ( 18 ' in the case of $V i$ ) between the first use of ' $\mathrm{X} \%$ of $\mathrm{Y} \%$ ' and the first use of the term 'multiplication'.

For instance, $T$, who had correctly used a percentage after 19' in Phase 1, had to be strongly accompanied to identify the role of multiplication in this physical situation. This backing up process was not very far from a transmissive input on behalf of the 
interviewer. To had just said that with two layers only half of the light was transmitted, as compared to a filter with one layer, but he had also realized that 'yellow' hardly changed when passing from one to two layers:

$\begin{array}{ll}\text { Int 23' } 30: & \text { There is a small problem here, a conflict. You just said the yellow doesn't } \\ & \text { disappear, well, it gets more intense, then, if it is half (of the intensity } \\ & \text { that disappears after two layers) ... then, err ... well. } \\ \text { To : } & \text { Very soon there would be nothing left. } \\ \text { Int : } & \text { Therefore you've a problem with that; I'm going to help you a bit. Say } \\ & \text { you have two robbers. I'm the first one, there's another behind me. I, } \\ & \text { the first robber, tell you: 'Give me ninety per cent of your money'. } \\ & \text { You've got a hundred euros, you give me ninety, so you've got only } \\ & \text { ten per cent left. The next robber says the same thing: 'Give me } \\ & \text { ninety per cent of what you have'. But you don't have a hundred } \\ & \text { euros anymore, you just have ten, and he still wants ninety per cent of } \\ & \text { what you have. In all, how much will you have? Ten percent after me, } \\ \text { The guy will leave you ten per cent of ... } & \text { Then per cent. } \\ \text { Int : } & \text { Ten per cent, hence he will not leave you much. } \\ \text { To : } & \text { One per cent of the total. } \\ \text { Int : } & \text { Yes, ten per cent of ten per cent, that makes one per cent. What oper- } \\ & \text { ation did you do? You've done ... ten per cent of ten per cent, which } \\ \text { To : } & \text { operation is it? } \\ \text { Int (ending her } & \text { A division by ... } \\ \text { previous sentence): } & \text { Ten per cent of ten per cent? } \\ \text { To: } & \text { Arr, a multiplication. } \\ \text { To : } & \text { Y multiplication by less than one. }\end{array}$

After this painstaking exchange, $T o$ 's difficulties were not yet behind him. He showed that he could calculate various values for a transmission curve corresponding to two layers, and even find that the shape of the curve changed with the number of layers of the filter. However, 3' after his first use of the word 'multiplication', he still looked reluctant to situate himself in a multiplicative paradigm. Interestingly, doing a calculation and understanding deeply the status of the corresponding operation were two different things:

Int, 26'20: You have narrowed ...

To: $\quad$ The peak

Int: The peak. What's your impression when switching to the multiplicative? You have told me several times that you were seeing subtractions in your head.

To: $\quad$ Yes

Int: $\quad$ And here ...

To: $\quad$ Err, mmm Yees

Int : $\quad$ Is there something that ...

To: $\quad$ Even after having done this (a multiplication) right from the beginning, I wouldn't have interpreted it as a multiplication. 
In the end, very synthetic comments were expressed by most of interviewees, as if things were suddenly very clear. Thus:

Mi 24'25 : Given that it is proportional, ... (adding filters) we will end by selecting the spectral band of the greatest transmission factor.

Th 33'21: We've just seen that differences increased when layers were added.

Mi 34'20 : Yes, finally, yes, once we discussed proportions, the fact that one filter lets eighty per cent pass, hence two filters let eighty per cent of eighty per cent pass. Yes, that's really clear. So now we can understand the fact of increasing the number of layers. (Int: mathematical operation?) Multiplication.

Ch 27'48: It's everywhere, multiplication.

As for To, he was very affirmative in his last comment about multiplication (in this part):

Int, 3133 : Do you prefer it if we say eighty per cent of eighty per cent, or eighty per cent times eighty per cent?

To : $\quad$ It's the same thing

With $V i$, as with $T o$, there was a long delay before the idea of a multiplicative approach was accepted. The interviewer had to introduce the idea herself (28'05), with $V i$ constantly arguing that 'it comes down to a subtraction' or 'a division'. But retrospectively, $V i$ was very critical concerning the rule presented at the beginning of the interview, even if the interviewer had not pronounced the word 'subtractive':

Vi 35’05 : Showing the subtraction, so to speak, of colours, and coming back afterwards to something that comes down to percentages, it's rather, err, I don't know if you should've presented it like that. (...) For a student who is not used to it, it might be very disturbing.

We see this strong critique has an indicator that $V i$ had then reached a vivid perception of the difference between a subtractive and a multiplicative approach.

Finally, once they had acknowledged the importance of multiplication in analysing multilayer filters, all of the students answered, although with some doubt in the case of $\mathrm{Vi}$, that the colour of a transparent medium might change depending on its thickness, because the shape of the spectrum of transmitted light would itself change with this variable.

\section{The last phases: transferring and generalization}

Table 4 displays, for each interviewee, the occurrences of the main themes selected for our analysis (Table 1) during the last three phases of the interview: Oil, Atm and Gene.

In this second part of the interview, the whole question seems to be that of seeing the medium under study as a filter for the light which finally enters the observer's eye.

Concerning the oil, this comprehension was straightforward:

Mi 1'04: The liquid can be seen as a superimposition of layers. 
save for $C h$ :

Ch 12'37 : We don't have a filter, there (...) but there is re ... There is also reflection, there is not only transmission.

By contrast, most of the interviewees had some difficulty in seeing the atmosphere as a filter. Only two ( $M i$ and $V i$ ) were able to suggest the Sun as an example for a change in colour due to the thickness of an absorbing medium.

What students commonly say is that the atmosphere diffuses (more) 'blue', whereas 'red' and 'green' are less diffused. Such expressions seem to evoke a sorting procedure and bring students back to the theme of subtraction, at the expense of the multiplicative approach. Thus:

Ya 14'32 : I see what hasn't been diffusively reflected. It's a dispersive medium, it's not a filter.

Int $14^{\prime} 51$ : When you're told that the sky is blue, the blue light is diffusively reflected, which mathematical operation does that make you think of, with respect to the incoming light?

To : $\quad$ Subtraction. What is transmitted is the rest.

Int : It's clearly subtraction?

To : $\quad$ Yes.

Vi 27'03 : You see colours disappear, that's subtracting, there's no way around that.

Th was able to reconcile the ideas of selective diffusion and of multiplicative transmission:

Th 4'40 : Up to now, we've been given an explanation relying on a difference in diffusion ( ... This doesn't seem incompatible with what we've just seen.

Th 6'05: In this case the photon doesn't disappear, it's diffusively reflected somewhere else (...). We can keep using it (the previous analysis), even if it's not the same phenomenon.

Int : $\quad$ Even if the photon doesn't disappear?

Th: $\quad$ Yes

Int 7'20: Hence, can I speak of a curve of absorption or something of the sort, for what comes from the Sun?

Th : $\quad$ Not of absorption, no, but of transmission, yes.

In this non obvious conceptual path from subtraction by diffusion to a view focused on transmission and selective multiplication, the photons probably played a disturbing role. Indeed, understanding light as a discontinuous entity does not a priori facilitate a view centered on selective multiplication:

Ya 32'45 : Just transmittance. For me, there's, an atom will absorb or diffuse. Say, it will absorb or it will diffuse, or it will just let something pass, it won't react.

Int : Hence your reasoning is not so much on collective phenomena, probability and so on, but more focused on one photon.

Ya: $\quad$ Yes

Int : $\quad$ So, the multiplicative aspect, $(\ldots)$, when you see one of them (photons) doing this or that, the multiplicative aspect err ... is not very salient.

Ya 32'54 : I don't know why I thought of multiplication. 
Globally, once a given situation is interpreted as giving rise to a filtering process, there is no difficulty in calling on and applying the multiplicative procedure just discussed, as witnessed by the numerous symbols ${ }^{*}$ in Table 4 .

Some comments attest to a conscious and explicit understanding of the multiplicative status of absorption and of its outcomes for the selection of radiations.

Mi 30'50 : Filtering isn't a global dimension for the spectrum, it's really a multiplication.

Vi 10': Small values get smaller more quickly than big values.

This does not exclude subsequent hesitations, as with To, who was destabilized by one of his own statements:

To 22'34: One layer takes a given percentage, two layers will take this percentage plus this percentage once more.

Int : $\quad$ Plus

To : $\quad$ Plus this percentage. We just said it was a multiplication. No, will take you this percentage of this percentage. Yes, that's it.

Or, as with Ya, quoted earlier:

Ya 32'44 : I don't know why I thought of multiplication.

To sum up, the part of the interview devoted to the transfer of the students' recent conceptual acquisition to new situations evidences some difficulties: Subtraction remains the more natural paradigm to analyse selective diffusion by the atmosphere. Once a situation is seen as a case of filtering, students show both a relative facility in their procedure and the persistence of some hesitation. Conciliating subtraction or even the 'addition of subtractions' (To 18'30, part 1) or division (Mi 23'50, part 1), with multiplication seems to occur after a challenging pathway.

\section{Gene phase}

All of the students more or less quickly expressed that a function that may account for the phenomena observed during this interactive pathway is the exponential. The interviewer sometimes used a very directive style during this phase, considerably buttressing this conclusion by interventions such as:

Int : When the change in a quantity versus abscissa ( $x$, for a small " $d x$ ”) is proportional to the quantity itself, what is the function representing the value of this quantity versus abscissa?

Nevertheless, no particular resistance was observed in this respect among the interviewees, as if most of the conceptual work was behind them. To even spoke of a 'natural' conclusion,

To 30' : Exponential function as we have just seen it, it's natural, definitely!

whereas some brief but significant comments were also collected:

Mi 29'32 : Not bad!

Th 15’30 : Aaah !!! 


\section{Mca phase}

The last phase of the interview was orientated by the interviewer towards a discussion at a meta-cognitive level. Students were asked briefly to rate their gain in understanding and their interest and/or intellectual satisfaction at the end of the teaching interview.

All of the students save $V i$ (rating ' 1 or 2') expressed very positive feelings, either with their ratings (between $3 / 4$ and $4 / 4$, see Table 4 ) ) and/or with their comments:

Mi 30’38 : (Satisfied?) ah yes! Moreover, it will enable me, if I have the opportunity, to explain what's going on in a more pedagogic and realistic way. (rating 3/4)

To 26'02 : I am very satisfied. (no rating)

Ch 22 ' $10:$ Ah, this is very interesting. (rating 'nearly $4 / 4$ ').

Th $17^{\prime} 05$ : I won't give any mark (yet), but it would be a very good one, and I am intellectually very satisfied, and I end this interview with greater accuracy, that means that it's been useful.

Ya 30'50: The design is, I think, rather good (..) even if that's not the part of physics I prefer, it makes us understand better. (rating 3/4)

Such answers were sometimes only a confirmation of feelings that had been spontaneously expressed previously, and have already served as examples:

Mi 34'20 in first phase: Yes, finally, yes, once we discussed proportions, the fact that one filter lets eighty per cent pass, hence two filters let eighty per cent of eighty per cent pass. Yes, that is really clear. So now we can understand the fact of increasing the number of layers. (Int: mathematical operation?) Multiplication.

We also pinpointed a trend that had already been observed (Mathe \& Viennot, 2009; Viennot \& de Hosson, 2012a; Viennot \& Décamp, 2013), which consists in responding first in terms of self-esteem, as if the expression 'intellectual satisfaction' meant 'satisfaction with his/her own responses' $(M i, Y a$ and $C h)$ :

Ch 21'16 :I will express myself a bit more clearly next time.

The opposite feeling was also expressed:

Th 17'26:In fact, if I'd been right at once, I would've been more frustrated. (rating 3,75/4)

A striking point is that some students were able to situate very precisely their conceptual gains.

Ya 18'15 : Even before doing it (the operation), I knew it was multiplicative. But going on to seeing the atmosphere as a filter, that's something I wouldn't have done, before.

Ya 30'18: The atmosphere as a filter, I had no idea of looking at it that way.

To 26'04 : Even after having done this (a multiplication) right from the beginning, I wouldn't have interpreted this as a multiplication.

Th 22'12:I wouldn't have spontaneously used the word multiplication, I did not reason like that before coming here. (...) I might use the operation with the right data, but if I were asked for an explanation, I would never have used the word multiplication.

Int 22 '50 : It didn't seemed obvious to you?

Th : $\quad$ No, not at all (...) Now that it's over, it seems simple. 
A need to go further was expressed, particularly by the only dissatisfied student:

Vi 24'12: This makes me want to go further.

Relevant questions were raised about the teaching of colour phenomena:

To 26'34 : Given this, should we tell our students, should we use the law of additivity bla bla bla! Is it correct to use it? No, it's true, additivity is OK, it's for subtractivity ... (that there is a problem).

Note that some remarks in this register had been made in the previous phases:

Vi 35'04 (already cited). Showing the subtraction, so to speak, of colours, and coming back afterwards to something that comes down to percentages, it's rather, err, I don't know if you should've presented it like that. (... ) For a student who is not used to it, it might be very disturbing.

This, we suggest, shows how a conceptual improvement may trigger a critical attitude, a phenomenon that was already pinpointed in the previous studies just cited.

\section{Recapitulation and final remarks}

Our investigation may yield information on several levels.

Despite the very limited number of our interviewees, the non-obviousness of a multiplicative approach concerning the absorption of light seems amply confirmed as a hypothesis. It has been observed that the most natural paradigm for these students, when commenting on either the usual rules for the action of pigments on light or those concerning filters, was subtractive. Confronted with the first experiment with solid filters of regularly incremented thicknesses, nearly all of the interviewees had serious difficulties in anticipating that the transmission curve would change with the number of layers. They also took time before bringing to bear percentages in order to explain why the shape of this curve changes. It was still more difficult, for some students, to consider their calculations of ' $\mathrm{X} \%$ of $\mathrm{X} \%$ ' as a multiplication.

The reason why access to the targeted comprehension seems so tortuous is not, we suggest, that the topic is formally very complex. After all, the conceptual target comprises only two main elements: each filtering layer 'multiplies' the incoming intensity by the same factor (smaller than one, or a percentage), and this factor is wavelengthdependent. It might be, rather, that the common view about a diminution-i.e. something has been 'taken off' as with a subtraction-acts as a stumbling block, and powerfully screens the multiplicative formalism.

From a methodological standpoint, our processing of the interviews suggests that, concerning this topic, we should not use overly simple indicators. For instance, some curves drawn by students before the experiment might be considered as correct, whereas a multiplicative approach was far from being consistently used by those students. The same might be said of students who performed a multiplication to find the value of the transmission factor of a filtering strip for one wavelength without understanding that this process was to be conducted for each wavelength separately; of students speaking of $\mathrm{X} \%$ or $\mathrm{Y} \%$ without realizing that a multiplication was involved 
in the corresponding calculation; or even of a student who had shown all the signs of a satisfying comprehension in this regard and declared soon after: 'I don't know why I thought of a multiplication'.

From a conceptual viewpoint, it seems that we have to renounce describing simply the transition of the students from a subtractive to a multiplicative approach, as if this were an event that we might localize in time. This said, several indicators were collected, mostly at the end of the interview, which attest to a noteworthy state of comprehension. Among these indicators, the most reliable might be, we suggest, some meta-cognitive comments. Indeed, several students admitted that they had made a big step between their first use of the idea and their present integration of the multiplicative approach.

Along the same line, the critical comments about the 'subtractive' label used for colour synthesis with pigments or filters are symptomatic of a real appropriation of the multiplicative approach. Previous investigations (Mathé \& Viennot, 2009; Viennot \& de Hosson 2012a; Viennot \& Décamp, 2013) suggest that students need to reach a threshold of comprehension before adopting a critical attitude. This lends some credibility to the link we are tempted to see between expressing a retrospective critique and having made notable conceptual progress. Finally, final statements in terms of intellectual satisfaction clearly indicate a significant intellectual change on the part of students who previously had proved capable of expressing possible disagreement or unease.

In this context, it is difficult to have a very precise idea about what was decisive in the interaction with each of the students, and that might at least partly explain their final state of comprehension. At least we can say that the first experiment with solid filters, followed by opportunities for transfer to liquid and gaseous filtering materials, provided a fruitful basis for the discussion with interviewees. Given the prototypical situation with filters of regularly incremented thicknesses, the calculations needed were extremely simple. But they are simple only when a multiplicative approach is adopted. With only one filter, there is no particular point in shifting from a subtractive view to a multiplicative one. By contrast, the relevance of the multiplicative approach is patent with several regularly incremented thicknesses. Moreover, the analysis then constitutes a direct illustration of what engenders an exponential dependency, which contributes to show how fruitful the multiplicative approach may be.

The goal of this investigation was to analyse students' comprehension of our conceptual target and their reactions to the interviewer's input. Further research might be now devoted to a teaching-learning sequence informed by our research. We have good reason to think that it is worth designing and evaluating an appropriate CDIP for this topic, in formats and variants adapted to particular contexts and constraints. The characteristics of a CDIP enunciated above, we suggest, do matter here: content/concept centred, interactive and progressive-progressivity referring here to the ideas of a patient construction, taking into account both obstacles and the time required to somewhat stabilize a new intellectual acquisition, given the students' ZPD.

Concerning students' intellectual satisfaction, beyond results that are still very limited, a question has been reactivated by this investigation. With the possibility of 
conceptual development that was opened by analogous CDIPs, a type of event was observed in the previous studies just cited: the triggering of a critical stance and a renewed exigency in students. This effect also occurred here. This link between conceptual development and a critical attitude is, we suggest, a crucial phenomenon to be explored further. To say the least, there are not many investigations exploring how this connection may develop along with a search for intellectual satisfaction. We suggest that more investigations be focused on this theme.

\section{Acknowledgements}

In the framework of the MUSE Project (More Understanding with Simple Experiment, EPS-PED http:/www.eps.org), Andreas Mueller and Gorazd Planinsic have run two workshops based on this CDIP (Viennot and de Hosson, 2013) with one of the authors (Viennot \& Mueller, 2013). Fruitful discussions are gratefully acknowledged.

\section{References}

Artigue, M. (1994). Didactical engineering as a framework for the conception of teaching products. In R. Biehler, R. W. Scholz, R. Sträßer, \& B. Winkelmann (Eds.), Didactics of Mathematics as a Scientific Discipline (pp. 27-39). Dordrecht: Kluwer Academic Publishers.

Brousseau, G., Brousseau, N., \& Warfield, V. (2008). Rationals and decimals as required in the school curriculum Parts 3 Rationals and decimals as linear functions. The fournal of Mathematical Behavior, 27, 153-176.

Champagne, A. B., Gunstone, R. F., \& Klopfer, L. E. (1985a). Effecting changes in cognitive structure among physics students. In L. West \& L. Pines (Eds.), Cognitive structure and conceptual change (pp. 163-187). Orlando: Academic Press.

Champagne, A. B., Gunstone, R. F., \& Klopfer, L. E. (1985b). Instructional consequences of students' knowledge about physical phenomena. In L. West \& L. Pines (Eds.), Cognitive structure and conceptual change (pp. 61-90). Orlando: Academic Press.

Chauvet, F. (1996). Teaching colour: Designing and evaluation of a sequence. European fournal of Teacher Education, 19(2), 121-136.

Chauvet, F. (1999). STTIS Project. Colour sequence University "Denis Diderot", LDAR (Laboratoire de didactique André Revuz); and STTIS (Science Teacher Training in an Information Society) web sites: Retrieved January 10, 2013 from http://www.lar.univ-paris-diderot.fr/ sttis_p7/color_sequence/page_mere.htm

Goldstein, E. B. (2010). Encyclopedia of perception. Thousand Oaks, CA: Sage Publications.

Hewson, P. W., \& Hewson, M. G. (1988). An appropriate conception of teaching science: A view from studies of science learning. Science Education, 72(5), 597-614.

de Hosson, C., \& Kaminski, W. (2007). Historical controversy as an educational tool: Evaluating elements of a teaching-learning sequence conducted with the 'Dialogue on the ways that vision operates'. International fournal of Science Education, 29(5), 617-642.

Komorek, M., \& Duit, R. (2004). The teaching experiment as a powerful method to develop and evaluate teaching and learning sequences in the domain of non-linear systems. International Fournal of Science Education, 26(5), 619-633.

Kreft, S., \& Kreft, M. (2007). Physicochemical and physiological basis of dichromatic colour. Naturwissenschaften, 94, 935-939. 
Martinez-Borreguero, G., Pérez-Rodríguez, A. L., Suero-López, M. I., \& Pardo-Fernández, P. J. (2013). Detection of Misconceptions about colour and an experimentally tested proposal to combat them. International fournal of Science Education, 35(8), 1299-1324.

Mathé, S., \& Viennot, L. (2009). Stressing the coherence of physics: Students', journalists' and science mediators' reactions. Problems of education in the 21st century, 11(11), 104-128.

Olivieri, G., Torosantucci, G., \& Vicentini, M. (1988). Coloured shadows. International fournal of Science Education, 10(5), 561-569.

Osborne, R., \& Gilbert, J. K. (1980). A method for investigating concept understanding in science. European Fournal of Science Education, 2(3), 311-321.

Planinsic, G. (2004). Color Light mixer for every student. The Physics Teacher, 42, 138-142.

Planinsic, G., \& Viennot, L. (2010). Shadows: stories of light. Retrieved from http://eps. org/> education $>$ muse

Strauss, A., \& Corbin, J. (1990). Basics of qualitative research: Grounded theory, procedures and techniques. Thousand Oaks, CA: Sage publications.

Viennot, L. (2006). Teaching rituals and students' intellectual satisfaction. Physics Education, 41, $400-408$.

Viennot, L., \& Décamp, N. (2013). Analysing texts about radio carbon dating: co-development of conceptual understanding and critical attitude, oral presentation, ESERA, Nicosia.

Viennot, L. (1979). Spontaneous reasoning in elementary dynamics. European fournal of Science Education, 2, 206-221.

Viennot, L., \& de Hosson, C. (2012a). Beyond a dichotomic approach, the case of colour phenomena. International fournal of Physics Education, 34(9), 1315-1336.

Viennot, L., \& de Hosson, C. (2012b). Colour Phenomena and Partial Absorption, Published by the MUSE group (More Understanding with Simple Experiments), EPS-PED. Retrieved from http://eps.org/>education > muse

Viennot, L., \& de Hosson, C. (2013). Colour phenomena and selective absorption: the role of thickness of absorbing medium, Published by the MUSE group (More Understanding with Simple Experiments), EPS-PED. Retrieved from http://eps.org/>education $>$ muse

Viennot, L., \& Mueller, A. (2013). The selective absorption of light. Physics Education, 700-701.

Vollmer, M., \& Gedzelman, S. D. (2006). Colours of the Sun and Moon: the role of the optical air mass. European fournal of Physics, 27, 299-309.

Vygotsky, L. (2012). Thought and language. Cambridge: MIT Press. 


\section{Appendix colour phenomena: classical rules}

Here the colours are associated with 'thirds of the spectrum'

Separating the various radiations that constitute 'white' light gives a 'spectrum'. The spectrum of white light ranges from $\lambda=400 \mathrm{~nm}$ to $\lambda=700 \mathrm{~nm}$. ( $\lambda$ : wavelength in empty space; $1 \mathrm{~nm}=10^{-9} \mathrm{~m}$ )

Here the spectrum is divided diagrammatically into

three equal parts

Coloured lights with a spectrum corresponding to a third of the

preceding one are seen respectively as

red in the long wavelengths

green in the medium wavelengths

blue in the short wavelengths

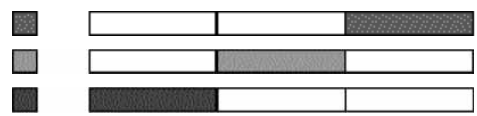

Additive mixing: Combining these three lights in various proportions produces a wide range of colours and, when the proportions are right, white

Adding two of these lights in correct proportion gives respectively a light seen as

yellow if you add red light and green light

cyan, if you add blue light and green light

magenta, if you add red light and blue light

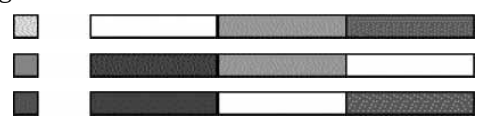

Absorbing role of filters or pigments A filter (or a pigment) absorbs a part of the spectrum of white light:

a yellow filter absorbs blue light (a third) and diffusely reflects green and red lights

a cyan filter absorbs red light (a third) and diffusely reflects

blue and green lights

a magenta filter absorbs green light (a third) and diffusely reflects blue and red lights 